\title{
Optimisation of ultrasound assisted extraction of antiacetylcholinesterase and antioxidant compounds from manuka (Leptospermum scoparium) for use as a phytomedicine against Alzheimer's disease
}

\author{
Hafiz Majid ${ }^{1,2}$ and Filipa V.M. Silva ${ }^{1,3 *}$ \\ ${ }^{1}$ Chemical and Materials Engineering Department, University of Auckland, Private Bag 92019, Auckland 1142, New Zealand \\ ${ }^{2}$ Faculty of Science and Natural Resources, Universiti Malaysia Sabah, 88400 Kota Kinabalu, Sabah, Malaysia \\ ${ }^{3}$ LEAF, Instituto Superior de Agronomia, Universidade de Lisboa, Tapada da Ajuda, 1349-017 Lisboa, Portugal \\ *Corresponding author: filipavinagresilva@gmail.com \\ (Received for publication 28 March 2020; accepted in revised form 5 November 2020)
}

\begin{abstract}
Background: Alzheimer's disease is a progressive mental deterioration related to ageing and senility. Approved drugs that inhibit acetylcholinesterase (AChE) enzyme activity in the human brain are one of the ways to control the natural progression of this disease. The present study reports on the optimisation of ultrasound-assisted extraction of antiacetylcholinesterase and antioxidant compounds from manuka leaves using response surface methodology.

Methods: A Box-Behnken design was used to investigate the effect of extraction temperature $\left(40-60^{\circ} \mathrm{C}\right)$, time $(1-20 \mathrm{~min})$, and ethanol concentration (30-70\%) on AChE inhibition, antioxidant activity, and extraction yield.

Results: The values of AChE, radical scavenging activity (RSA) and yield predicted by the models generated were similar to the experimental values. Extraction time, ethanol concentration and temperature were significant in all the responses. Optimum extraction conditions for maximum AChE inhibition (74\%), RSA (79\%) and yield (50\%) were successfully validated experimentally and the $\mathrm{IC}_{50}$ of the optimised extracts were reduced to 28.5 (from 66.0) and 2.37 (from 32.4 ) $\mu \mathrm{g} /$ $\mathrm{mL}$ for AChE and antioxidant activity, respectively. The optimisation enabled an increase in the extraction yield from $21 \%$ to $49 \%$.

Conclusions: In view of the significant bioactive properties determined, with possible beneficial effects on memory deficit, we would encourage the use of the manuka leaf extract for the development of new phytopharmaceuticals to improve brain function and control dementias such as Alzheimer's disease. One other application could be as a beverage for the preparation of tea infusions.
\end{abstract}

Keywords: Leptospermum scoparium; plant extracts; yield; acetylcholinesterase; enzyme inhibition

\section{Introduction}

With an ageing population mental disability or dementia are increasing problems among the elderly affecting more than 20 million people worldwide. Alzheimer disease $(A D)$ is the most prevalent dementia affecting more than 20 million people worldwide. The disease is highly associated with age, with $3 \%$ of affected people aged 65 to 74 years, and $47.2 \%$ for elders above 85 years old (Taylor et al. 2002; Adewusi \& Steenkamp 2011; Huang et al. 2010). The most developed pharmacological approach for the symptomatic treatment of $\mathrm{AD}$ is the inhibition of acetylcholinesterase (AChE) (Mukherjee et al. 2007). Based on the cholinergic hypothesis, the aim of this treatment is to increase the level of acetylcholine 
(ACh) in synaptic regions in order to restore cognitive functions (Nordberg \& Svensson 1998). Tacrine was the first approved drug, followed by various AChE inhibitors including donepezil, galantamine and rivastigmine (Schelterns \& Feldman 2003). In recent years, there has been significant interest in natural products in health relevant areas, particularly in developing anti AD agents from medicinal plants. Because of this, a large number of plants and their crude extracts have been studied for their AChE inhibition activity (Syad \& Devi 2014).

Leptospermum scoparium, also known as manuka or "tea tree", grows as a shrub or small tree across New Zealand (Forster \& Forster 1776). It is about $2 \mathrm{~m}$ tall but occasionally reaches $4 \mathrm{~m}$ or more. There is already a great commercial interest and several plantations in New Zealand for the production of the manuka honey, known worldwide not only for its flavour, but also for its medicinal properties. Early reports show that Māori used the bark, leaves, seeds, and sap of manuka for food, medicine and timber (Porter \& Wilkins 1999). In medicinal use, different preparations of the leaves have been taken orally, directly chewed, applied as salve, or inhaled to treat cold, dysentery, as vapor baths, and to ease internal and external pains (Brooker et al. 1987; Stephens et al. 2005). In New Zealand, there is growing commercial interest on manuka products, especially in the essential oils distilled from the leaves part. Beneficial properties of the oils such as potent antimicrobial activity, including antifungal, antioxidant, insecticidal, and anthelminthic activities were demonstrated (Lis-Balchin et al. 2000; Porter \& Wilkins 1999). Interestingly, previous studies in this area revealed that the crude extracts from Leptospermum scoparium leaf inhibit AChE activity (Majid \& Mathew 2015, Majid \& Silva 2020a). The chemical composition study from dichloromethane extract of manuka leaf showed traces of flavonoids and triterpenoids compounds, which may be the factor attributed to the inhibition activity (Häberlein \& Tschiersch 1994; Mayer 1990). It is known that some class of triterpenoids and flavonoids have significant anticholinesterase activity, and are regarded as promising candidates to be used as cholinesterase inhibitors in clinical practice (Ahmed et al. 2013).

Ultrasound or ultrasonic assisted extraction (UAE) has been known to increase the extraction efficiency of bioactives from a wide range of plant materials (Hossain et al. 2012). This extraction technique has been used to extract substances such as terpenoids, polysaccharides, polyphenols, flavonoids, and other class of compounds from different parts of the plant (Pan et al. 2012; Wang et al. 2008; Cacace \& Mazza 2003). The advantages of UAE are reduced extraction time and solvent use, and higher extraction yield (Majid \& Silva, 2020b). Ultrasound is more efficient than a conventional extraction method as it allows more effective mixing and faster mass/energy transfer (Silva et al. 2007). Through ultrasound technique, the production of plant extracts is enhanced by the acoustic cavitation that breaks the cells' walls mechanically, greatly facilitating the mass transfer between the solid and liquid phase (Wang et al. 2008). Despite the simplicity of this technique, many factors such as solvent type, solvent concentration, extraction time, extraction temperature, and solvent to solid ratio need to be optimised to achieve maximum efficacy of the extraction (Liyana-Pathirana \& Shahidi 2005). Response surface methodology (RSM) is used for developing, improving and optimising processes involving several variables. Compared to the one factor at a time optimisation approach, which is more laborious and time consuming, RSM is able to reduce the number of experiment trials needed to study the interactions of multiple variables (Majid \& Silva, 2020b). The rationale for the use of RSM is to determine the optimum conditions for the extraction and to generate a mathematical model, which relates AChE inhibition with the extraction parameters.

The main objectives of this study were to optimise the UAE parameters namely the solvent concentration, the extraction time, and the temperature using RSM, aiming to maximise the extraction of antiAChE related compounds from manuka leaves and the yield of plant extract produced. In addition, the antioxidant activity of the extracts produced was also quantified for the same experimental design. Models to predict AChE inhibition, yield of extract production and radical scavenging activity (RSA) as a function of extraction parameters were generated and validated. The specific objectives were: 1 . To select the best solvent and appropriate range of extraction parameters to extract antiacetylcholinesterase (AChE) compounds from manuka leaves; 2 . To study the effect of temperature, extraction time, and ethanol concentration on AChE inhibition using response surface methodology; 3 . To experimentally validate the optimum extraction conditions; 4 . To determine the $\mathrm{IC}_{50}$ concentrations for AChE inhibition and DPPH RSA of the optimised extracts; and 5 . To compare $\mathrm{IC}_{50}$ values of optimised extracts with non-optimised extracts.

\section{Methods \\ Plant materials}

Dried Leptospermum scoparium leaves were purchased from a local herbal supplier "Kiwiherbs Ltd", Wellington, New Zealand. The material was ground into fine particles using a grinder and sifted through a $0.25 \mathrm{~mm}$ sieve to obtain a uniform particle size. The material was then vacuum-sealed and stored in a dark condition at room temperature until use in the extraction experiments.

\section{Ultrasound assisted extraction}

For all the extractions carried out, one gram of dried and ground manuka leaves were extracted using 50 $\mathrm{mL}$ of solvent in a beaker (fixed ratio of $20 \mathrm{mg}$ plant/ $\mathrm{mL}$ solvent). The process of ultrasonic extraction was performed by using a $200 \mathrm{~W}$ and $24 \mathrm{KHz}$ frequency ultrasonic processor equipped with a $3 \mathrm{~mm}$ diameter micro tip (UP200S, Hielscher Ultrasonics GmbH, Teltow, Germany). This sonotrode was dipped about half way into the mixture contained in the beaker (plant leaves + solvent). The maximum acoustic energy intensity for this sonotrode is $460 \mathrm{~W} / \mathrm{cm}^{2}$ according to the specifications of the manufacturer manual (Hielscher 2007). As the area 
of $3 \mathrm{~mm}$ tip is $0.0707 \mathrm{~cm}^{2}$, a value of $32.5 \mathrm{~W}$ is obtained for the acoustic power at the maximum amplitude of $210 \mu \mathrm{m}$. The power/energy input was configured by setting the amplitude of the sonicator probe, as higher amplitude is proportional to higher energy/power. As $50 \mathrm{~mL}$ of mixture was sonicated, the maximum acoustic power density was $0.65 \mathrm{~W} / \mathrm{mL}$ (which corresponds to $210 \mathrm{~mm}$ amplitude).

Prior to each experiment, the temperature of the solvent inside the beaker was stabilised at the experiment's set temperature, then the dry manuka leaves were added and sonication time started. During the sonication, the beaker with the mixture was submerged in an ice water bath. The extraction mixture temperature was continuously monitored and kept approximately constant $\left( \pm 2^{\circ} \mathrm{C}\right)$ by adding ice water to the bath surrounding the beaker.

\section{Preparation of plant extract and determination of extraction yield}

Following the extraction, the samples of solvent containing the crude extract were filtered (Whatman \#1 filter paper) to obtain a clear extract solution and remove solid residues of the plant. Then the clear solution was dried at $50^{\circ} \mathrm{C}$ under vacuum using a rotary evaporator (Rotavapor R-215, BÜCHI Labortechnik AG, Flawil, Switzerland) to remove the solvent and obtain the crude extract. The extracts were then further air-dried in fume hood at room temperature until constant weight is obtained. The final weight of the dried crude extract was recorded for the determination of extraction yield, and then stored at $-20^{\circ} \mathrm{C}$ for further analysis. The yield of extraction in percentage of extraction was calculated as follows:

Extraction yield $(\%)=\frac{\text { weight of dried crude extract }(g)}{\text { weight of manuka leaves powder }(g)} \times 100$

\section{Overview of experiments}

The optimisation of ultrasound assisted extraction (UAE) from manuka leaves was performed in three stages. The first stage involved the selection of appropriate extraction solvent and the identification of variables with a significant effect on the extraction yield, AChE inhibition and RSA. For this set of experiments, the effects were analysed by changing one factor at a time while keeping the other variables constant: 0.52 $\mathrm{W} / \mathrm{mL}$ of acoustic power density, $50^{\circ} \mathrm{C}$ temperature, 10 min extraction time, $50 \%$ ethanol-water solvent. In the second stage of experiments, further optimisation of extraction conditions (Section Experimental design and response surface methodology) was carried out through response surface methodology (RSM) using a Box-Behnken experimental design to investigate the simultaneous effect of extraction temperature $\left(40-60^{\circ} \mathrm{C}\right)$, extraction time (1-20 $\mathrm{min}$ ) and ethanol concentration $(30-70 \%)$ on plant extraction yield (\%), plant extract AChE inhibition (\%) and antioxidant activity assessed by DPPH radical scavenging activity (\%). The ultrasound amplitude was set to $168 \mu \mathrm{m}$ which corresponds to $0.52 \mathrm{~W} / \mathrm{mL}$ of acoustic power density in all the experiments. Lastly in the third stage of experiments optimised conditions predicted by the models for maximum inhibition of AChE and RSA were tested experimentally and the experimental $\mathrm{IC}_{50}$ concentrations were determined for those conditions (Section Validation of model).

\section{The effect of different ultrasound extraction parameters on AChE inhibition and RSA of manuka extracts}

\section{Solvent for extraction}

Five different solvents (acetone, chloroform, ethyl acetate, methanol, and ethanol) were examined at $100 \%$ concentration. One gram of dried and ground manuka leaves were extracted in a beaker containing $50 \mathrm{~mL}$ of each solvent. The extraction was performed for $10 \mathrm{~min}$ at $50^{\circ} \mathrm{C}$, using acoustic power density of $0.52 \mathrm{~W} / \mathrm{mL}$. The samples were filtered and freed of solvent by rotary evaporation. The crude extracts were stored then stored at $-20^{\circ} \mathrm{C}$ prior to analysis. For this set of experiments two $\mathrm{IC}_{50}$ values of AChE inhibitions and DPPH RSA were determined for each solvent by carrying out triplicate tests for four concentrations of the dried extract and performing a non-linear regression (details shown in Section Determination of $I C_{50}$ extract concentrations).

\section{Ethanol concentration}

Mixtures of ethanol-water were selected as extraction solvents. The concentration of ethanol-water was set at $0 \%, 30 \%, 50 \%, 80 \%$ and $100 \%$. Dried and ground manuka leaves $(1 \mathrm{~g})$ were extracted with the different concentrations of ethanol $(50 \mathrm{~mL})$. The extraction performed at fixed extraction conditions for $10 \mathrm{~min}$ at $50^{\circ} \mathrm{C}$, with acoustic power density of $0.52 \mathrm{~W} / \mathrm{mL}$. The samples were filtered and freed of solvent by rotary evaporation. The crude extracts were stored then stored at $-20^{\circ} \mathrm{C}$ prior to analysis. The inhibition of AChE and RSA for an extract concentration of $50 \mu \mathrm{g} / \mathrm{mL}$ were determined in triplicates and average \pm standard deviation presented.

\section{Extraction temperature}

Manuka leaves were extracted at different temperature of $30,40,50,60$, and $70^{\circ} \mathrm{C}$. One gram of dried manuka leaves were sonicated with $50 \mathrm{~mL} 50 \%$ ethanol-water solvent. The extraction was achieved at $10 \mathrm{~min}$ using acoustic power density of $0.52 \mathrm{~W} / \mathrm{mL}$. The samples were filtered and evaporated to dryness by using a rotary evaporation. The crude extracts were stored at $-20^{\circ} \mathrm{C}$ prior to analysis. The inhibition of AChE and RSA for an extract concentration of $50 \mu \mathrm{g} / \mathrm{mL}$ were determined in triplicate and average \pm standard deviation presented.

\section{Extraction time}

Extraction of manuka leaves were executed for a time ranging from 2 to 60 minutes. One gram of dried manuka leaves were extracted with $50 \mathrm{~mL}$ of ethanolwater $(50 \%)$. The extraction was done at $50^{\circ} \mathrm{C}$ using 
acoustic power density of $0.52 \mathrm{~W} / \mathrm{mL}$. The samples were filtered and dried by rotary evaporation to obtain crude extracts. The crude extracts were stored at $-20{ }^{\circ} \mathrm{C}$ prior to analysis. The inhibition of AChE and RSA for an extract concentration of $50 \mu \mathrm{g} / \mathrm{mL}$ were determined in triplicates and average \pm standard deviation presented.

\section{Acoustic power density}

Extraction sonication was performed at a setting of 0.13 , $026,0.39,0.52$, and $0.65 \mathrm{~W} / \mathrm{mL}$. Dried manuka leaves ( $1 \mathrm{~g}$ ) were extracted with $50 \%$ concentration of ethanol at different acoustic power density. The extraction was performed for $10 \mathrm{~min}$ at $50^{\circ} \mathrm{C}$. The samples were filtered, dried using rotary evaporation and crude extracts were then stored at $-20^{\circ} \mathrm{C}$ prior to consequent analysis. The inhibition of AChE and RSA for an extract concentration of $50 \mu \mathrm{g} / \mathrm{mL}$ were determined in triplicates and average \pm standard deviation presented.

Response surface methodology to further investigate the combined effect of extraction temperature, time and ethanol concentration on AChE inhibition, extraction yield and RSA: experimental design, optimisation and experimental validation of model predictions

The extraction parameters were further optimised using RSM based on a three level, three variables Box Behnken Design (BBD). Temperature $\left(\mathrm{T},{ }^{\circ} \mathrm{C}\right)$, time $(\mathrm{t}, \mathrm{min})$, and ethanol concentration in water (E, \%) were the independent variables optimised for the extraction of manuka leaves, while the dependent variables were the yield of extraction, and the AChE inhibition (\%) and DPPH radical scavenging activity RSA (\%) for a dried extract concentration of $50 \mu \mathrm{g} / \mathrm{mL}$. The extraction temperature between 40 and $60^{\circ} \mathrm{C}$, extraction time between 1 to $20 \mathrm{~min}$, and ethanol concentration in water from 30 to $70 \%$ were investigated. The variables and their levels are coded at three levels, -1 (the lowest value), 0 (midpoint value) and +1 (highest value). The complete design with actual experimental parameters is presented in Table 1. The design experiment includes 17 experimental points, including five replicates that were used for estimation of pure error sum of squares. Each experimental condition was performed in triplicates and average values ( \pm SD) were taken as response for the dependent variables. Once the experiments were performed, all the response data were fitted a quadratic polynomial equation.

The experimental results of the response surface were analysed using Design-Expert Version 12 software (StatEase Inc., Minneapolis, MN, USA). Analysis of variance (ANOVA) was then carried out for each response to determine the statistical significance and suitability of the model. The significances of all terms were analysed by calculating the $\mathrm{F}$-value and $\mathrm{P}$-value $(\mathrm{P}<0.05)$, while the quality of the equation models was expressed by the adjusted coefficient of determination (adjusted $R^{2}$ ). The

TABLE 1: Experimental results of Box-Behnken design used to investigate the effect of ethanol concentration, ultrasound extraction temperature and time on the AChE inhibition, radical scavenging activity (RSA) and yield of manuka leaf extracts $(50 \mu \mathrm{g} / \mathrm{mL}$ dried extract concentration, $0.52 \mathrm{~W} / \mathrm{mL}$ acoustic power density).*

\begin{tabular}{ccccccc}
\hline Run & $\begin{array}{c}\text { T, Temp } \\
\left({ }^{\circ} \mathbf{C}\right)\end{array}$ & $\begin{array}{c}\text { t, time } \\
\text { (min) }\end{array}$ & $\begin{array}{c}\text { E, ethanol } \\
\text { concentration (\%) }\end{array}$ & $\begin{array}{c}\text { AChE } \\
\text { inhibition (\%) }\end{array}$ & $\begin{array}{c}\text { DPPH RSA } \\
\text { (\%) }\end{array}$ & Yield (\%) \\
\hline 1 & 50 & 1 & 30 & $29.87 \pm 7.00$ & $50.99 \pm 2.57$ & $28.87 \pm 0.89$ \\
2 & 60 & 10.5 & 30 & $42.10 \pm 3.62$ & $71.46 \pm 3.71$ & $32.72 \pm 0.78$ \\
3 & 60 & 1 & 50 & $51.53 \pm 3.48$ & $61.67 \pm 3.79$ & $28.79 \pm 0.75$ \\
4 & 60 & 20 & 50 & $61.36 \pm 4.97$ & $74.48 \pm 3.18$ & $44.28 \pm 1.36$ \\
5 & 50 & 20 & 30 & $52.79 \pm 3.17$ & $58.30 \pm 4.44$ & $31.68 \pm 1.81$ \\
6 & 40 & 20 & 50 & $71.22 \pm 2.39$ & $60.73 \pm 4.58$ & $38.30 \pm 0.61$ \\
7 & 50 & 1 & 70 & $54.63 \pm 2.97$ & $46.45 \pm 4.72$ & $28.69 \pm 1.07$ \\
8 & 60 & 10.5 & 70 & $55.76 \pm 3.56$ & $76.16 \pm 2.43$ & $44.67 \pm 1.11$ \\
9 & 50 & 10.5 & 50 & $72.59 \pm 4.66$ & $68.73 \pm 3.38$ & $41.26 \pm 0.74$ \\
10 & 40 & 10.5 & 30 & $34.95 \pm 2.75$ & $59.65 \pm 3.35$ & $32.16 \pm 1.66$ \\
11 & 50 & 10.5 & 50 & $73.25 \pm 2.09$ & $67.02 \pm 5.14$ & $40.58 \pm 0.61$ \\
12 & 50 & 10.5 & 50 & $67.20 \pm 3.42$ & $68.71 \pm 2.95$ & $40.52 \pm 1.24$ \\
13 & 50 & 10.5 & 50 & $69.17 \pm 2.92$ & $70.81 \pm 7.64$ & $41.20 \pm 1.05$ \\
14 & 40 & 10.5 & 70 & $61.14 \pm 3.85$ & $57.54 \pm 2.62$ & $39.58 \pm 0.70$ \\
15 & 50 & 20 & 70 & $65.18 \pm 2.55$ & $64.58 \pm 2.77$ & $46.20 \pm 2.18$ \\
16 & 40 & 1 & 50 & $38.46 \pm 2.60$ & $55.89 \pm 2.79$ & $34.80 \pm 1.55$ \\
17 & 50 & 10.5 & 50 & $71.25 \pm 4.42$ & $69.29 \pm 3.44$ & $40.40 \pm 0.91$ \\
\hline
\end{tabular}

* AChE is the acetylcholinesterase Alzheimer's Disease enzyme, and RSA is the DPPH radical scavenging activity; AChE, RSA and yield data are mean \pm standard deviation of triplicate experiments for the same processing conditions. 
relationship between the dependent and independent variables was presented using a response surface plot. To obtain optimum extraction (factor) conditions, each response (AChE inhibition, DPPH RSA, yield) was set to "maximum" to achieve the highest value, while the factors (temperature, time, ethanol concentration) were set within the ranges investigated in the RSM study, by using the point prediction post analysis tool of Design Expert statistical software.

\section{Validation of model}

The optimum conditions of extraction for maximum AChE inhibition, RSA, and yield were predicted from the polynomial models generated by RSM as explained in previous Section. Then, the inhibition of AChE, RSA at $50 \mu \mathrm{g} / \mathrm{mL}$, and yields at optimum conditions were determined experimentally. Finally, the $\mathrm{IC}_{50}$ values of the optimised crude dried extracts and reference compounds with respect to their AChE inhibition and RSA were also determined.

\section{Enzyme inhibition and DPPH radical scavenging activity \\ Chemicals}

Chromatography-grade methanol and ethyl acetate and analytical-grade ethanol and acetone were obtained from ECP Laboratory Research and Chemicals, New Zealand. Analytical-grade chloroform was obtained from Sigma-Aldrich (NZ). Phosphate buffer, potassium hyroxide, 5,5'-dithiobis-(2-nitrobenzoic acid) (DTNB), sodium hydrogen carbonate, acetylthiocholine iodide substrate (ATChI) acetylcholinesterase from human erythrocytes (AChE), dimethyl sulfoxide, 2,2-diphenyl1-picrylhydrazyl (DPPH), donepezil and ascorbic acid standards were purchased from Sigma-Aldrich (NZ). Deionised water was used for all experiments.

\section{Acetylcholinesterase activity and inhibition}

The assay for measuring AChE activity was measured by the microplate assay using Ellman's colorimetric method and modified by Rauter et al. (2007) (Rauter et al. 2007). Manuka extract mixtures were prepared in concentrations of $2.2 \mathrm{mg} / \mathrm{mL}$ in $12.5 \%$ DMSO-water which gives a final test concentration of $50 \mu \mathrm{g}$ of extract/ $\mathrm{mL}$. Reagents were prepared as follows: $0.1 \mathrm{M}$ phosphate buffer was freshly prepared before each analysis (136.1 mg of $\mathrm{KH}_{2} \mathrm{PO}_{4}$ in $10 \mathrm{~mL}$ water, adjusted at $\mathrm{pH} 8.0$ with $\mathrm{KOH}$ ); $0.01 \mathrm{M}$ DTNB solution (3.96 mg DTNB in $1 \mathrm{~mL}$ water containing $1.5 \mathrm{mg}$ sodium hydrogen carbonate). $0.022 \mathrm{M}$ ATChI solution (6.4 mg ATChI in $1 \mathrm{~mL}$ water); $1.32 \mathrm{Unit} / \mathrm{mL}$ AChE solution (4.4 mg of AChE enzyme (10 mL, $1.02041 \mathrm{U}$ ) in $1 \mathrm{~mL}$ buffer at $\mathrm{pH}$ 8.0.

The assay was achieved by adding $5 \mathrm{ml}$ of manuka extract, $200 \mathrm{ml}$ phosphate buffer, $5 \mathrm{~mL}$ of AChE enzyme, and $5 \mathrm{ml}$ DTNB reagent in a 96-well microplate, which was kept for $15 \mathrm{~min}$ at $30^{\circ} \mathrm{C}$. Then, $5 \mathrm{~mL}$ of ATChI substrate solution was added to the mixture to start the enzymatic reaction. Absorbances were determined using a microplate reader (EnSpire Multimode Plate Reader, PerkinElmer, Turku, Finland) at $405 \mathrm{~nm}$ for every $45 \mathrm{~s}$, 6 times consecutively at a controlled temperature of $30^{\circ} \mathrm{C}$. The experiments were conducted in triplicate. The rate of enzyme inhibition was calculated using the equation:

$$
\text { Enzyme Inhibition }(\%)=100-\left[\left(\frac{V_{\text {extract }}}{V_{\max }}\right) \times 100\right]
$$

Where $V_{\text {extract }}$ is the rate of colour change of the extract ( $\Delta \mathrm{abs} / \Delta$ time) and $V_{\max }$ is the maximum rate of colour change of the blank ( $\Delta$ abs $/ \Delta$ time) not containing any inhibition compound.

For the $\mathrm{IC}_{50}$ study, the dried crude extract of manuka and donepezil (control) were initially dissolved in 12.5\% DMSO and diluted in distilled water to obtain final test concentrations between 1 to $1000 \mathrm{mg} / \mathrm{mL}$. No inhibition was detected at the highest concentration of DMSO used (12.5\%). Donepezil is a standard Alzheimer drug and was used as reference for comparison purposes.

\section{Radical scavenging antioxidant activity}

The antioxidant activity of plant extracts was determined using free-radical scavenging effect on the 2,2-diphenyl1-picrylhydrazyl (DPPH) radical with slight modification (Rauter et al. 2012). Methanolic DPPH solution (100 $\mathrm{mM}$ ) was prepared at least a day before analysis, this is to ensure a fully dissolved solution with a stable wavelength measurement. Manuka extract mixtures were prepared in concentrations of $1 \mathrm{mg} / \mathrm{mL}$ in $12.5 \%$ DMSO-water giving a final test concentration of $50 \mu \mathrm{g} / \mathrm{mL}$. Similar to $\mathrm{AChE}$, for the $\mathrm{IC}_{50}$, four different concentrations of the same extract were tested in triplicates. An aliquot of $10 \mathrm{ml}$ manuka extract was mixed with $190 \mathrm{~mL}$ of DPPH solution in a clear 96-well microplate. The mixture was shaken vigorously before being kept in dark at room temperature for $40 \mathrm{~min}$. All the test solutions were measured at $517 \mathrm{~nm}$ using a microplate reader. The results were shown as percentage of DPPH inhibition; these values represent the radical scavenging capacity of the extracts. The percentage of DPPH radical scavenging activity (RSA, \%) is calculated as follows:

$R S A(\%)=\frac{A b s_{\text {blank }}-A b s_{\text {extract }}}{A b s_{\text {blank }}} \times 100$

where $A b s_{\text {blank }}$ is the absorbance of DPPH solution without extract after 40 min while $A b s_{\text {extract }}$ is the absorbance after 40 min of the DPPH solution containing the extract mixtures.

\section{Determination of IC $_{50}$ extract concentrations}

The $\mathrm{IC}_{50}$ value of plant extract is the concentration of dried extract that inhibits $50 \%$ of enzyme activity or causes $50 \%$ RSA. It was estimated from the inhibition/ antioxidant results for different concentrations (3 replicates for each of the four extract concentrations tested). By plotting the \% inhibitions/RSA against the extract concentrations $(\mu \mathrm{g} / \mathrm{mL})$, the $\mathrm{IC}_{50}$ value was determined through a nonlinear regression analysis using GraphPad Prism 6 (GraphPad Software Inc, La Jolla, 
CA, USA). The results for $\mathrm{IC}_{50}$ were reported with $95 \%$ confidence interval limits. Donepezil and ascorbic acid $\mathrm{IC}_{50}$ values were also determined, as those are reference pure compounds for Alzheimer AChE inhibition and antioxidant, respectively. The $\mathrm{IC}_{50}$ of references are expected to be much lower than those found for manuka crude extracts, as they are pure compounds.

\section{Results and Discussion}

The first section presents single factor experiments AChE inhibition and RSA results for a dried extract concentration of $50 \mu \mathrm{g} / \mathrm{mL}$. Based on those results, the effects of ethanol concentration $(30-70 \% \mathrm{v} / \mathrm{v})$, extraction temperature $\left(40-60^{\circ} \mathrm{C}\right)$ and time (1-20 min) on AChE inhibition and antioxidant activity of manuka extracts were considered for the response surface methodology study and results are presented in second section. Last section shows the experimental validation of optimal conditions predicted by the RSM models.

\section{Single factor experiments: effects on AChE inhibition and RSA activity}

\section{Effect of the extraction solvent on $I C_{50}$ of manuka extracts}

Selection of solvent can play an important role in extraction of targeted compounds from complex samples. In the first step of this study, the efficiency of five commonly used solvent, acetone, chloroform, ethyl acetate, methanol, and ethanol on the extraction of antiAChE and antioxidant compounds from manuka leaves was compared. The comparison was made based on $\mathrm{IC}_{50}$ values, which is the extract concentration needed to inhibit $50 \%$ of the enzymatic activity and $50 \%$ RSA (Figure 1). A low $\mathrm{IC}_{50}$ value is preferable as it represents good activity of a tested extract. Methanol and ethanol were the most efficient solvents in the recovery of antiAChE compounds when compared to ethyl acetate, chloroform, and acetone. Although methanol $\mathrm{IC}_{50}=31.6$

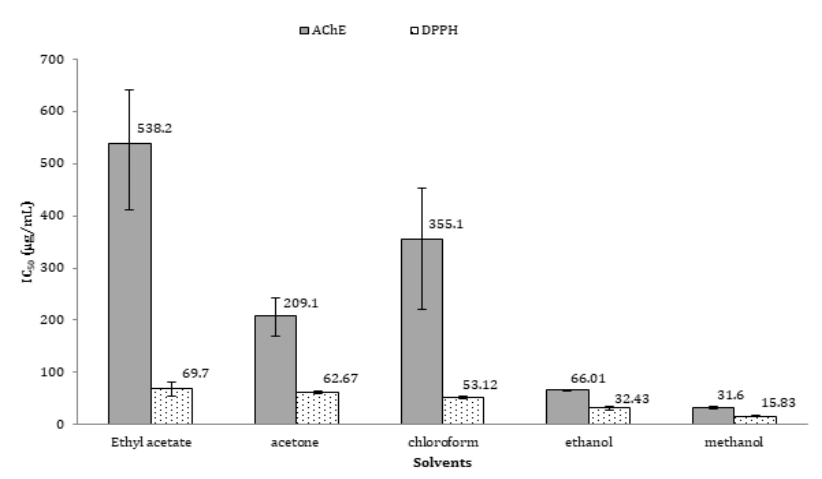

FIGURE 1: Effect of solvent type on AChE inhibition and DPPH RSA of manuka extracts produced with $0.52 \mathrm{~W} / \mathrm{mL}-50^{\circ} \mathrm{C}$ ultrasound for 10 min. Results are $\mathrm{IC}_{50}$ values ( $\mu \mathrm{g}$ dried extract/ $\mathrm{mL}$ causing $50 \%$ enzyme inhibition or RSA). The error bar represents the values of $95 \%$ confidence interval. $\mu \mathrm{g} / \mathrm{mL})$ was slightly better than ethanol $\left(\mathrm{IC}_{50}=66.01\right.$ $\mu \mathrm{g} / \mathrm{mL}$ ), as methanol is toxic, ethanol was chosen as the extraction solvent due to its major advantages from environmental and human consumption safety aspects, in addition to recommendation by the US Food and Drug Administration for extraction purposes. The manuka extracts prepared with ethyl acetate, acetone and chloroform were not so good in extracting the bioactive compounds for AChE inhibition, presenting much higher IC $_{50}$ concentrations (209 to $538 \mu \mathrm{g} / \mathrm{mL}$ ). The different extraction efficiencies of these solvents may be explained by their differences in polarities, which showed strong preference to solvents with high polarity (Tian et al. 2013). In terms of antioxidant activity, methanol and ethanol produced extracts comparable to that of the standard antioxidant ascorbic acid ( $\mathrm{IC}_{50} 12.01$ $\mu \mathrm{g} / \mathrm{mL}$ ). The significant differences between the range of antioxidant and antiAChE results demonstrated that the latter may be contributed by a much narrower class of compound(s), which were extracted specifically by certain type of solvents. Regarding RSA results, the $\mathrm{IC}_{50}$ for all solvents tested was very similar, with $\mathrm{IC}_{50}$ results ranging from 15.8 to $69.7 \mu \mathrm{g} / \mathrm{mL}$.

\section{Effect of ethanol concentration}

Regarding the extraction solvent, different proportions of ethanol-water were investigated. Figure 2 shows the effect of ethanol concentration at $0,30,50,80$, and $100 \%$ on AChE inhibition (\%) and DPPH RSA (\%) of 50 $\mu \mathrm{g} / \mathrm{mL}$ manuka extracts produced after $10 \mathrm{~min}, 0.52$ $\mathrm{W} / \mathrm{mL}$, and $50^{\circ} \mathrm{C}$ extraction. The results show that the extractions of antiAChE and antioxidant compounds are highly dependent on the ethanol concentration in water. The highest activity was observed for $50 \%$ ethanol concentration (70.3\%), followed by $80 \%$ ethanol (54.1\%), while the lowest activity was registered for pure water $(12.7 \%)$. Similar trend was registered for

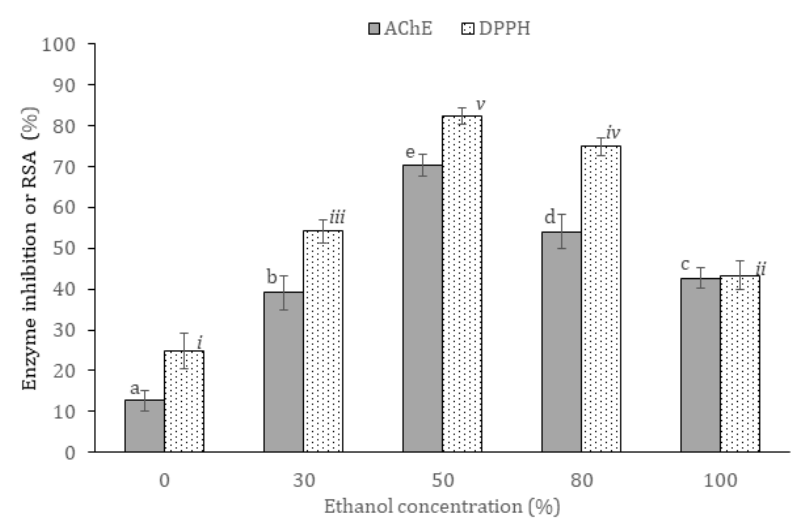

FIGURE 2: Effect of ethanol concentration in water on AChE inhibition and DPPH radical scavenging activity of $50 \mu \mathrm{g} / \mathrm{mL}$ manuka extracts produced using $50^{\circ} \mathrm{C}$ and $0.52 \mathrm{~W} / \mathrm{mL}$ acoustic power density for 10 minutes (the error bars are standard deviations; results with different letters for AChE or roman numbers for RSA are significantly different). 


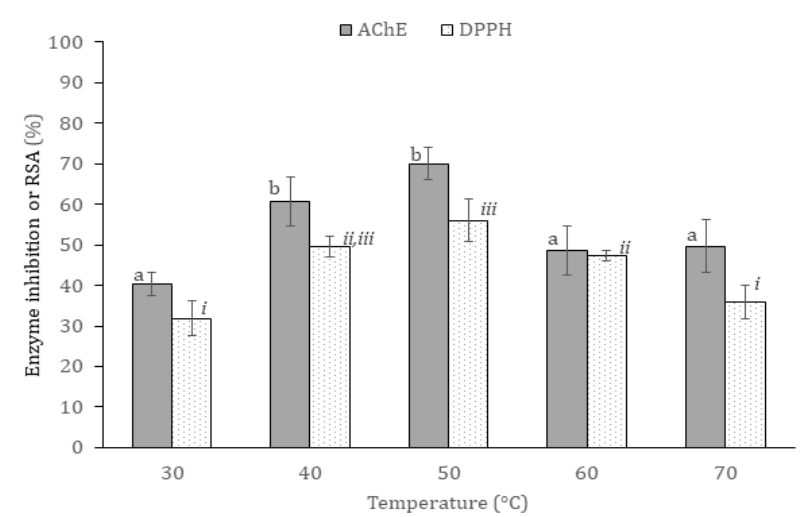

FIGURE 3: Effect of extraction temperature on AChE inhibition and DPPH radical scavenging activity by $50 \mu \mathrm{g} / \mathrm{mL}$ of manuka extracts produced using $50 \%$ ethanol concentration for $10 \mathrm{~min}$ at $0.52 \mathrm{~W} / \mathrm{ml}$ acoustic power density (the error bars are standard deviations; results with different letters for AChE or roman numbers for RSA are significantly different).

RSA results. The combination of water with other organic solvents is able to produce moderately polar solvents that have more universal capabilities, ensuring the extraction of many type of compounds (Chirinos et al. 2007). In addition, the existence of water also allowed an effective swelling of the plant, which further increase the surface area for solute-solvent contact (Yang \& Zhang 2008). A similar effect was found in the extraction of antioxidant compounds from wheat bran and peanut skins (Nepote et al. 2005; Wang et al. 2008).

\section{Effect of extraction temperature}

The selection of an appropriate range of extraction temperatures was also studied. The experiments were carried out at temperatures between 30 to $70^{\circ} \mathrm{C}$ under fixed extraction conditions. The effects of extraction temperature on AChE inhibition and DPPH RSA are shown in Figure 3. The activities for AChE inhibition and DPPH RSA increased when the temperature was increased from 30 to $40-50^{\circ} \mathrm{C}$ (AChE $70 \%$, RSA 56\%), and then declined at higher extraction temperature $\left(\geq 60^{\circ} \mathrm{C}\right)$. This is possibly due to the increase of molecular movement at higher temperature, which also increase the solubility that leads to higher extraction rate (Yang et al. 2010). However, extraction at temperature higher than $60^{\circ} \mathrm{C}$ reduced both responses. It may be explained by oxidation and degradation of compounds responsible for AChE inhibition and antioxidant properties in manuka extract solutions.

\section{Effect of extraction time}

Figure 4 shows the influence of extraction time on AChE inhibition and DPPH RSA. The figure compares the ultrasound extractions using 50\% ethanol-water concentration, at $50^{\circ} \mathrm{C}$ and $0.52 \mathrm{~W} / \mathrm{mL}$ for different treatment times $(2,5,10,20,30,40,50,60 \mathrm{~min})$. The

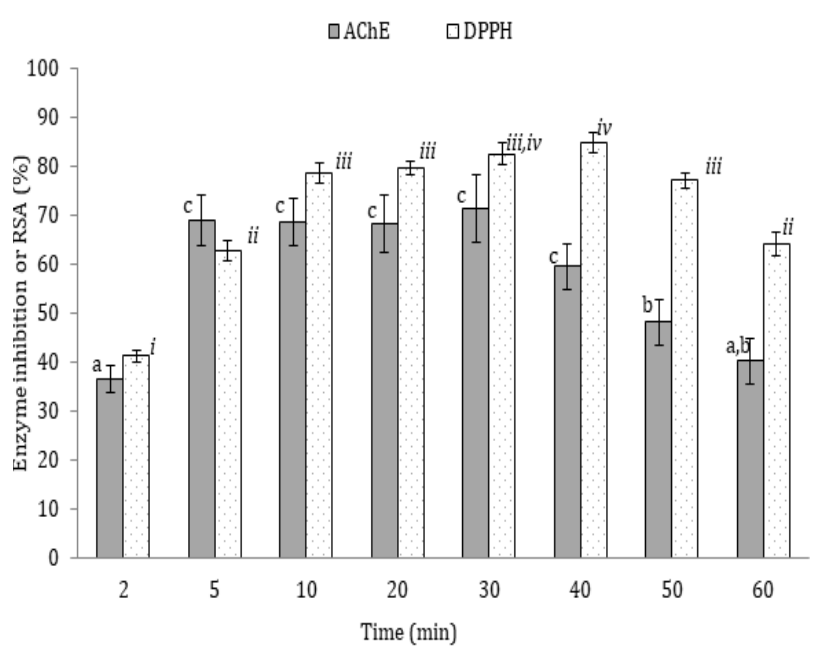

FIGURE 4: Effect of extraction time on AChE inhibition and DPPH radical scavenging activity by $50 \mu \mathrm{g} / \mathrm{mL}$ manuka extracts produced using $50 \%$ ethanol concentration at $50^{\circ} \mathrm{C}$ and 0.52 $\mathrm{W} / \mathrm{mL}$ acoustic power density (the error bars are standard deviations; results with different letters for AChE or roman numbers for RSA are significantly different).

results show that for antiAChE compounds, the extraction produced the maximum inhibition just after 5 minutes of ultrasound extraction (68.9\%). The extraction reached equilibrium from 10-30 min, then dropped after this point. For DPPH RSA, the response increased significantly in the initial $10 \mathrm{~min}(78.7 \%)$ with a maximum at $40 \mathrm{~min}$ extraction time (84.7\%), then RSA decreased from 40 to $60 \mathrm{~min}$. In both cases, the extraction process responses occur in three stages, rapid increase, slow/equilibrium, decrease stage. During the rapid increase stage, also known as "washing" phenomena, the cell wall of manuka leaves powder cracked within a certain period of time as the result of the acoustic cavitation effect, allowing better penetration of the solvent into the cells and enhancing the release of dissolved compounds out of the solid structure of the leaves (Tian et al. 2013). The "slow extraction" may be explained by the decrease in solvent's permeability into manuka cell structure, caused by the release of various impurities into the solvent during washing stage. Besides that, increasing solute content also lower the diffusion rate and mass transfer between the plant matrix into the solvent (Şahin and Şamlı 2013). The decreasing stage can be observed in AChE inhibition (after $30 \mathrm{~min}$ ) and antioxidant activity (after $40 \mathrm{~min}$ ). This decrease may have occurred due to the heating effect at $50^{\circ} \mathrm{C}$ of overexposure to ultrasound treatment that caused degradation of the active compounds present in the extracts (Şahin and Şamlı 2013). Therefore, with a negative response at longer extraction time, it is unnecessary to study beyond this range.

\section{Effect of acoustic power density}

The effect of acoustic power density $(0.13,0.26$, $0.39,0.52$, and $0.65 \mathrm{~W} / \mathrm{mL}$ ) on AChE inhibition and antioxidant activity of the manuka extracts was studied while setting the other parameters fixed as followed: 
$50 \%$ ethanol-water concentration, extraction time 10 min at temperature $50^{\circ} \mathrm{C}$. As shown in Figure 5, higher ultrasound acoustic power produced better results for both the responses in general, reaching a maximum for $0.52 \mathrm{~W} / \mathrm{mL}$ (69.6\% AChE inhibition, 80.8\% RSA). The ultrasound energy has great influence in the extraction of bioactive compounds from the leaves. It is known that the extraction of various substances plant material by sonication was achieved due to the presence of cavitation microscopic bubbles generated by ultrasonic waves travelling through the solvent. The type and amount of bubbles created are proportional to the amplitude, power and intensity of ultrasonic waves. The higher the ultrasound energy (amplitude) the greater the production of cavitation bubbles; the collapse of these bubbles are believed to produce high-shear gradients which disrupts the plant cell walls, this enhance the penetration of solvent into solid matrix and accelerate the release of active components into the extraction solvent, leading to a higher extraction efficiency (Tian et al. 2013). From the result, $168 \mu \mathrm{m}$ which is $0.52 \mathrm{~W} / \mathrm{mL}$ was chosen as the optimum amplitude/power density.

Experimental results for Box-Behnken design, polynomial models and response surface plots

The responses of AChE inhibition, DPPH RSA and extraction yield for the 17 experimental conditions are reported in Table 1 . The values of variables for each experimental design condition are also presented. The response of AChE inhibition varied from 29.9 \pm 7.0 to $73.3 \pm 2.1 \%$, DPPH RSA that was used to evaluate the antioxidant activity ranged between $46.45 \pm 4.72$ to $76.16 \pm 2.43 \%$, while extraction yield values ranged from $28.7 \pm 1.1$ to $46.20 \pm 2.2 \%$.

Multiple regression analysis was performed based on the results in Table 1 . The best mathematical model for each response was fitted by the statistical software.

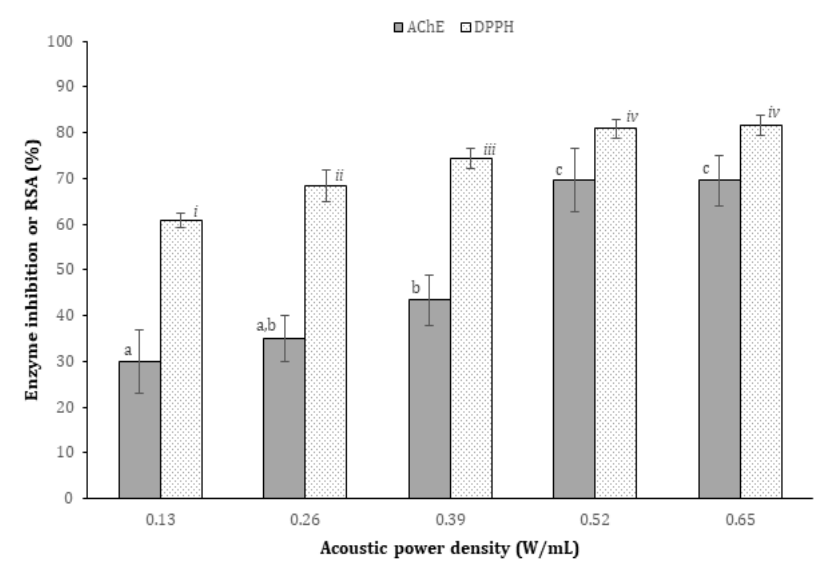

FIGURE 5: Effect of ultrasound acoustic power on AChE inhibition and DPPH radical scavenging activity by $50 \mu \mathrm{g} / \mathrm{mL}$ manuka leaves extracts produced using $50 \%$ ethanol in water concentration for $10 \mathrm{~min}$ at $50^{\circ} \mathrm{C}$ (the error bars are standard deviations; results with different letters for AChE or roman numbers for RSA are significantly different).
Equations 4-6 show the quadratic models for AChE inhibition, DPPH RSA and yield in terms of their real values $(T, t, E)$ :

AChE inhibition $(\%)=-353.6+10.07 * \mathrm{~T}+6.317 * \mathrm{t}+4.831 * \mathrm{E}-0.06000 * \mathrm{Tt}-$ $0.01550 * \mathrm{TE}-0.01618 * \mathrm{tE}-0.08600 * \mathrm{~T}^{2}-0.07172 * \mathrm{t}^{2}-0.03406 * \mathrm{E}^{2}$

DPPH RSA $(\%)=61.63-2.086 * T+1.813 * t+1.225 * E+0.01421 * t E+0.02713 * T^{2}$. $0.09321 * t^{2}-0.01347 * E^{2}$

Yield $(\%)=23.75-0.2616 * T-1.131 * t+0.7848 * E+0.03158 * T t+0.01934 * t E-$ $0.04276 * t^{2}-0.007773 * E^{2}$

The quality of the adjustments for each model was given by adj $\mathrm{R}^{2}$ and coefficient of variation (C.V.). For AChE inhibition the fit statistical indicators were 0.973 and $4.0 \%$, for DPPH RSA adj $\mathrm{R}^{2}$ was 0.906 and C.V. 3.98\% and yield adj $\mathrm{R}^{2}$ was 0.955 and C.V. 3.35\%, demonstrating acceptable models and reliability of the experimental results. A high F-value and P-value lower than 0.05 are also indicators of good models (and parameters significance). The ANOVA results show P-values $<0.0001$ for AChE inhibition, DPPH RSA and yield (Additional Files A-C).

Three-dimensional response surface plots are graphical representations of the regression equation, which provide a method to visualise the relationship between any two factors on selected responses. Based on the RSM polynomials, the 3D response surfaces were generated using Design-Expert software and 3 examples are show in Figure 6. In all response surface graphs the response (z-axis) was plotted against any two variables while the other factor was kept at its ' 0 ' level, the midpoint value of the range investigated $\left(50^{\circ} \mathrm{C}\right.$, $50 \%$ ethanol). In terms of AChE inhibition, time and ethanol concentration demonstrated quadratic effect on AChE inhibition (Figure 6a). At this temperature, the range of response varied between 28 to $75 \%$. At any time and ethanol concentration, AChE produced the highest inhibition at around 50\% ethanol water concentration and after 10 minutes of extraction. Figure $6 \mathrm{~b}$ shows the effect of temperature and time on DPPH RSA of manuka extracts. The DPPH RSA increased with increase of extraction temperature. The response curves demonstrated higher DPPH RSA at around medium extraction time $(10 \mathrm{~min})$. The 3D response of ethanol concentration and time on extraction yield was shown in Figure 6c. From the graph, it can be observed that lower concentration of ethanol concentration (30\%) produced no obvious increase in extraction yield ( $3 \%$ increment) within 20 minutes of extraction time. However, at higher ethanol, as in case of $70 \%$ concentration, the yield of extraction increased from $29 \%$ to $46 \%$ when extraction time increased from 1 to $20 \mathrm{~min}$.

Experimental validation of optimal conditions estimated by the RSM models

Using the models generated by the RSM analysis (Equations 4-6), the predicted $T, t$ and ethanol concentration which maximise the AChE inhibition, 
a) Temperature $=50^{\circ} \mathrm{C}$

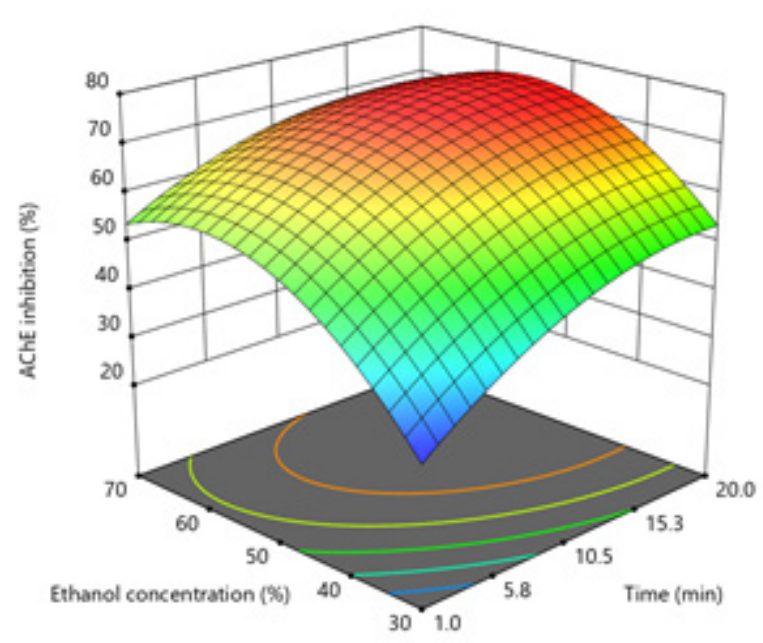

b) $50 \%$ Ethanol concentration

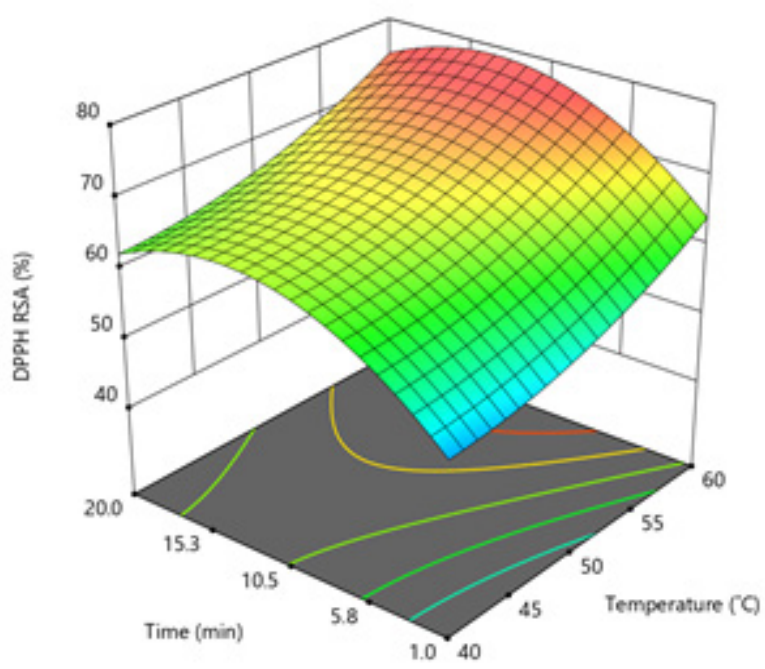

c) Temperature $=50^{\circ} \mathrm{C}$

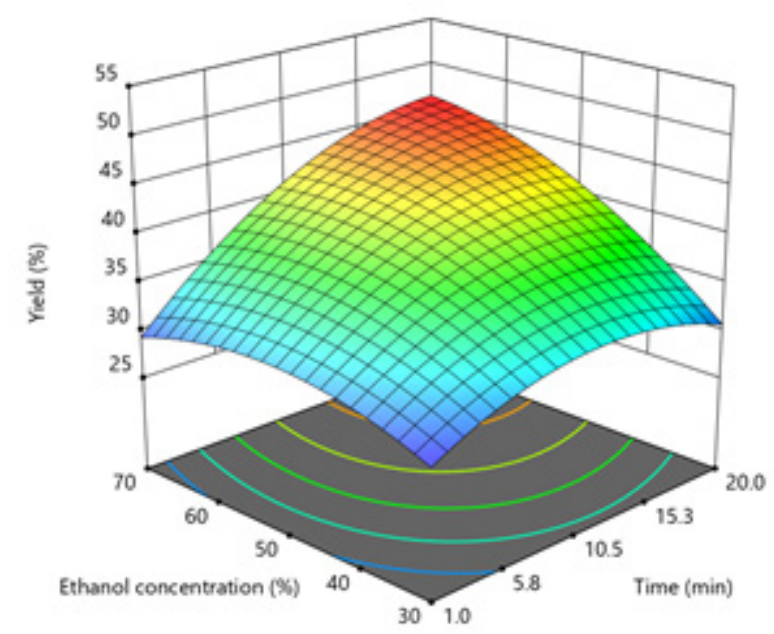

FIGURE 6: Response surface plots showing the effects of temperature $\left({ }^{\circ} \mathrm{C}\right.$ ), extraction time (min), and ethanol concentration (\%) on a) AChE inhibition (\%) by $50 \mu \mathrm{g} / \mathrm{mL}$ manuka extract, b) DPPH radical scavenging activity (\%) by $50 \mu \mathrm{g} / \mathrm{mL}$ manuka extract, and c) yield (\%). The rest of the variables were set at midpoint $\left(50^{\circ} \mathrm{C}, 10.5 \mathrm{~min}, 50 \%\right.$ ethanol $)$.

RSA activity and yield of extraction were estimated. Three different optimum extraction conditions for each response are shown in Table 2 together with the predicted and real experimental values. Optimum conditions were $50^{\circ} \mathrm{C}-15 \mathrm{~min}-50 \%$ ethanol for AChE inhibition, $60^{\circ} \mathrm{C}-$ $14 \mathrm{~min}-56 \%$ for DPPH radical scavenging activity and $60^{\circ} \mathrm{C}-20 \mathrm{~min}-70 \%$ ethanol for maximum extraction yield. Then, the three responses were experimentally determined for those optimum extraction conditions, to compare the predictions with real experimental results. The close values of predicted and experimental data (absolute errors $<2 \%$ ) show that the models are adequate tools to predict $\mathrm{AChE}$ inhibition, RSA and yield of manuka extracts.
The $\mathrm{IC}_{50}$ concentrations of optimised manuka extracts, and reference compounds were also determined experimentally and can be compared with those from non-optimised extracts (Table 3). Regarding AChE inhibition, the $\mathrm{IC}_{50}$ of ultrasound optimised manuka extract $(28.48 \mu \mathrm{g} / \mathrm{mL})$ was lower than the value determined for the ultrasound non-optimised extracts $(66.01 \mu \mathrm{g} / \mathrm{mL}$ obtained with $100 \%$ ethanol and 157.5 $\mu \mathrm{g} / \mathrm{mL}$ obtained with $100 \%$ water) and the extract obtained by maceration with $100 \%$ water $(148 \mu \mathrm{g} / \mathrm{mL})$ (Mathew 2015). Although the $\mathrm{IC}_{50}$ concentration of AChE inhibition for optimised manuka extract $(28.48 \mu \mathrm{g} / \mathrm{mL})$ was higher than the reference compound donepezil $(0.7551 \mu \mathrm{g} / \mathrm{mL})$, it still shows a comparable value as 
TABLE 2: Optimum ultrasound $(0.52 \mathrm{~W} / \mathrm{mL})$ extraction conditions from manuka leaves for maximum AChE inhibition, radical scavenging activity (RSA) and extraction yield: comparison of values predicted by the model and experimentally determined for a dried extract concentration of 50 $\mu \mathrm{g} / \mathrm{mL}$.

\begin{tabular}{lccccc}
\hline Responses & \multicolumn{3}{c}{ Optimum conditions } & \multicolumn{2}{c}{ Maximum values } \\
\cline { 2 - 6 } & $\begin{array}{l}\text { Temperature } \\
\mathrm{T}\left({ }^{\circ} \mathrm{C}\right)\end{array}$ & $\begin{array}{l}\text { time } \\
\mathrm{t}(\mathrm{min})\end{array}$ & $\begin{array}{l}\text { Ethanol } \\
\text { concentration E } \\
(\%)\end{array}$ & $\begin{array}{l}\text { RSM } \\
\text { Predicted }\end{array}$ & $\begin{array}{l}\text { Experimental } \\
\text { result }^{\mathrm{a}}\end{array}$ \\
\hline AChE (\%) & 50 & 15 & 50 & 74 & $72.69 \pm 3.84$ \\
RSA (\%) & 60 & 14 & 56 & 79 & $80.14 \pm 3.88$ \\
Yield (\%) & 60 & 20 & 70 & 50 & $49.19 \pm 2.08$ \\
\hline
\end{tabular}

${ }^{a}$ Mean \pm standard deviation of triplicate experiments for the same processing conditions

TABLE 3: Yields and $\mathrm{IC}_{50}$ concentrations for acetylcholinesterase (AChE) inhibition and radical scavenging activity (RSA) of manuka leaf extracts: comparison of ultrasound optimised extract with ultrasound non-optimised extracts, extract produced by maceration, and reference compounds for Alzheimer enzyme inhibition and antioxidant activity.

\begin{tabular}{|c|c|c|c|c|c|c|c|}
\hline \multirow{2}{*}{$\begin{array}{l}\text { Extraction } \\
\text { method }\end{array}$} & \multirow{2}{*}{$\begin{array}{c}\text { Acoustic } \\
\text { power } \\
\text { density } \\
(\mathrm{W} / \mathrm{mL})\end{array}$} & \multirow{2}{*}{$\begin{array}{l}\text { Temp. } \\
\left({ }^{\circ} \mathrm{C}\right)\end{array}$} & \multirow{2}{*}{$\begin{array}{l}\text { Time } \\
(\mathrm{min})\end{array}$} & \multirow{2}{*}{$\begin{array}{l}\text { Solvent and } \\
\text { concent. } \\
(\%)\end{array}$} & \multicolumn{2}{|c|}{$\mathrm{IC}_{50}(\mu \mathrm{g} / \mathrm{mL})^{\mathrm{a}}$} & \multirow[t]{2}{*}{ Yield (\%) } \\
\hline & & & & & AChE & DPPH RSA & \\
\hline $\begin{array}{l}\text { Optimised } \\
\text { ultrasound AChE }\end{array}$ & 0.52 & 50 & 15 & Ethanol 50\% & $\begin{array}{l}28.48 \\
\text { (25.43 to } 31.89 \text { ) }\end{array}$ & - & - \\
\hline $\begin{array}{l}\text { Optimised } \\
\text { ultrasound RSA }\end{array}$ & 0.52 & 60 & 14 & Ethanol 56\% & - & $\begin{array}{l}2.367 \\
(2.190 \text { to } 2.560)\end{array}$ & - \\
\hline $\begin{array}{l}\text { Optimised } \\
\text { ultrasound Yield }\end{array}$ & 0.52 & 60 & 20 & Ethanol 70\% & - & - & 49.19 \\
\hline $\begin{array}{l}\text { Non-optimised } \\
\text { ultrasound }\end{array}$ & 0.52 & 50 & 10 & Ethanol 100\% & $\begin{array}{l}66.01 \\
(64.59 \text { to } 67.45)\end{array}$ & $\begin{array}{l}32.43 \\
(29.03 \text { to } 36.23)\end{array}$ & nd \\
\hline $\begin{array}{l}\text { Non-optimised } \\
\text { ultrasound }\end{array}$ & 0.422 & 70 & 2.3 & Water $100 \%$ & $\begin{array}{l}157.5 \\
(142.2 \text { to } 174.4)\end{array}$ & nd & 21.10 \\
\hline Maceration $^{\mathrm{c}}$ & - & 70 & 40 & Water $100 \%$ & $\begin{array}{l}148.0 \\
\text { (138.3 to } 158.5)\end{array}$ & nd & 14.05 \\
\hline \multicolumn{8}{|l|}{$\begin{array}{l}\text { Reference } \\
\text { compounds }\end{array}$} \\
\hline Donepezil $^{\mathrm{b}}$ & - & - & - & - & $\begin{array}{l}0.7551 \\
(0.6129 \text { to } \\
0.9302)\end{array}$ & - & - \\
\hline Ascorbic acid ${ }^{b}$ & - & - & - & - & - & $\begin{array}{l}12.01 \\
(10.23 \text { to } 14.11)\end{array}$ & - \\
\hline
\end{tabular}

nd - not determined

${ }^{a} I C_{50}$ is the plant extract concentration presenting 50\% activity. The values inside parenthesis are the 95\% confidence interval

${ }^{b}$ Donepezil and ascorbic acid are known AChE inhibitor and antioxidant compounds, respectively, both used as references

${ }^{c}$ Mathew MB. 2015. Optimisation of plant extraction conditions for the inhibition of Alzheimer's disease enzyme acetylcholinesterase. Final Year Project 2015, Chemical and Materials Engineering Department, University of Auckland, New Zealand.

in a crude extract the active compound(s) was not purified. Regarding DPPH RSA, optimised manuka extract had lower value of $\mathrm{IC}_{50}(2.4 \mu \mathrm{g} / \mathrm{mL})$ than nonoptimised extract $(32.4 \mu \mathrm{g} / \mathrm{mL})$ and ascorbic acid $(12.0$ $\mu \mathrm{g} / \mathrm{mL}$ ), indicating potent antioxidant activity. The yield increased from 14\% (water maceration) and 21\% (ultrasound with water) to $49 \%$ (optimised ultrasound conditions with ethanol 70\%). 


\section{Conclusions}

Ultrasound assisted extraction offers an advantage for the extraction of antiAChE and antioxidant compounds from the leaf of manuka. Response surface methodology was successfully employed to optimise the extraction conditions. The quadratic models generated could predict accurately the effect of manuka leaf extraction on AChE inhibition, RSA and yield of extraction. Ethanol concentration, temperature and time affected all the responses individually and combined with some of the other variables. Studies involving the chemical analysis of extracts produced under optimum conditions, namely the identification of compounds responsible for biological activities are an important area of future research. In view of the significant bioactive properties of manuka extracts found in this study, with possible beneficial effects on memory deficit, we would encourage the use of the manuka leaf extract for the development of new phytopharmaceuticals to improve brain function and control dementias such as Alzheimer disease. One other application of manuka could be the preparation of tea infusions or incorporation as an ingredient in beverages or solid foods.

\section{Competing interests}

The authors declare that they have no known competing financial interests or personal relationships that could have appeared to influence the work reported in this paper.

\section{Authors' contributions}

HM planned and carried out the experiments and wrote the first draft of this manuscript. FS planned the experiments, revised the manuscript, supervised the overall research and journal submission/revision.

\section{Acknowledgements}

We thank the Ministry of Higher Education Malaysia, Government of Malaysia for a PhD Scholarship to HM. The authors acknowledge "The Biocide Tool Box for New Zealand Manufacturing Exporters", funded by the New Zealand Ministry of Business, Innovation and Employment.

\section{Additional Files}

Additional File A: AChE inhibition by manuka leaf extracts.

Additional File B: Antioxidant DPPH radical scavenging activity (RSA) by manuka leaf extracts.

Additional File C: Manuka leaves extraction yield.

\section{References}

Adewusi, E.A., Steenkamp, V. (2011). In vitro screening for acetylcholinesterase inhibition and antioxidant activity of medicinal plants from Southern Africa. Asian Pacific Journal and Tropical Medicine, 4(10), 829-835. 835. https://doi.org/10.1016/S19957645(11)60203-4

Ahmed, F., Ghalib, R.M., Sasikala, P., Ahmed, K.K.M. (2013). Cholinesterase inhibitors from botanicals. Pharmacognosy Reviews, 7(14): 121. https://doi. org/10.4103/0973-7847.120511

Brooker, S.G., Cambie, R.C., Cooper, R.C. (1987). New Zealand Medicinal Plants. New Zealand: Heinemann.

Cacace, J.E., Mazza, G. (2003). Optimization of extraction of anthocyanins from Black currants with aqueous ethanol. Journal of Food Science, 68(1), 240-248. https://doi.org/10.1111/j.1365-2621.2003. tb14146.x

Chirinos, R., Rogez, H., Campos, D., Pedreschi, R., Larondelle, Y. (2007). Optimization of extraction conditions of antioxidant phenolic compounds from mashua (Tropaeolum tuberosum Ruíz \& Pavón) tubers. Separation and Purification Technology, 55(2), 217-225. https://doi.org/10.1016/j. seppur.2006.12.005

Forster, J.R., Forster, G. (1776). Characteres Generum Plantarum quas in Itinere ad Insulas Maris Australis Collegerunt, Descripserunt, Delinearunt, Annis. London, White, Cadell \& Elmsley. 150 p. https:// doi.org/10.5962/bhl.title.4448

Häberlein, H., Tschiersch, K.P. (1994). Triterpenoids and flavonoids from Leptospermum scoparium. Phytochemistry, 35(3), 765-768. https://doi. org/10.1016/S0031-9422(00)90601-0

Hielscher. (2007). UP200S/UP400S: Instruction Manual. Hielscher Ultrasonics GmbH: Teltow, Germany.

Hossain, M.B., Brunton, N.P., Patras, A., Tiwari, B., O'Donnell, C.P., Martin-Diana, A.B., BarryRyan, C. (2012). Optimization of ultrasound assisted extraction of antioxidant compounds from marjoram (Origanum majorana L.) using response surface methodology. Ultrasonics and Sonochemistry, 19(3), 582-590. https://doi. org/10.1016/j.ultsonch.2011.11.001

Huang, L., Shi, A., He, F., Li, X. (2010). Synthesis, biological evaluation, and molecular modeling of berberine derivatives as potent acetylcholinesterase inhibitors. Bioorganic and Medicinal Chemistry, 18(3), 1244-1251. https://doi.org/10.1016/j. bmc.2009.12.035

Lis-Balchin, M., Hart, S.L, Deans, S.G. (2000). Pharmacological and antimicrobial studies on different tea-tree oils (Melaleuca alternifolia, Leptospermum scoparium or manuka and Kunzea ericoides or kanuka), originating in Australia and New Zealand. Phytotherapy Research, 14(8), 623-629. $\quad$ https://doi.org/10.1002/10991573(200012)14:8<623::AID-PTR763>3.0.CO:2-Z 
Liyana-Pathirana, C., Shahidi, F. (2005). Optimization of extraction of phenolic compounds from wheat using response surface methodology. Food Chemistry, 93(1), 47-56. https://doi. org/10.1016/j.foodchem.2004.08.050

Majid, H., Mathew, M. (2015). Optimized ultrasoundassisted water extraction from Leptospermum scoparium leaves containing acetylcholinesterase inhibitory activity. Presented In $9^{\text {th }}$ CIGR Section VI International Technical Symposium, Creating Value from Bioresources.

Majid, H, Silva, F.V.M. (2020a). Inhibition of enzymes important for Alzheimer's disease by antioxidant extracts prepared from 15 New Zealand medicinal trees and bushes. Journal of the Royal Society of New Zealand, 50(4), 538-551. https://doi.org/10. $\underline{1080 / 03036758.2020 .1741403}$

Majid, H, Silva, F.V.M. (2020b). Improvement of butyrylcholinesterase enzyme inhibition and medicinal properties of extracts of Aristotelia serrata leaves by ultrasound extraction. Food and Bioproducts Processing, 124, 445-454. https://doi. org/10.1016/j.fbp.2020.10.004

Mayer, R. (1990). Flavonoids from Leptospermum scoparium. Phytochemistry, 29(4), 1340-1342. https://doi.org/10.1016/0031-9422(90)85462-0

Mukherjee, P.K., Kumar, V., Houghton, P.J.(2007).Screening of Indian medicinal plants for acetylcholinesterase inhibitory activity. Phytotherapy Research, 21(12), 1142-1145. https://doi.org/10.1002/ptr.2224

Nepote, V., Grosso, N.R., Guzmán,C.A.(2005). Optimization of extraction of phenolic antioxidants from peanut skins. Journal of the Science of Food and Agriculture, 85(1), 33-38. https://doi.org/10.1002/jsfa.1933

Nordberg, A., Svensson, A.L. (1998). Cholinesterase inhibitors in the treatment of Alzheimer's Disease. Drug Safety, 19(6), 465-480. https://doi. org/10.2165/00002018-199819060-00004

Pan, G., Yu, G., Zhu, C., Qiao, J. (2012). Optimization of ultrasound-assisted extraction (UAE) of flavonoids compounds (FC) from hawthorn seed (HS). Ultrasonics Sonochemistry, 19(3), 486-490. https://doi.org/10.1016/j.ultsonch.2011.11.006

Porter, N.G., Wilkins, A.L. (1999). Chemical, physical and antimicrobial properties of essential oils of Leptospermum scoparium and Kunzea ericoides. Phytochemistry, 50(3), 407-415. https://doi. org/10.1016/S0031-9422(98)00548-2

Rauter, A.P., Branco, I., Lopes, R.G., Justino, J., Silva, F.V.M., Noronha, J.P., Cabrita, E.J., Brouard, I., Bermejo, J. (2007). A new lupene triterpenetriol and anticholinesterase activity of Salvia sclareoides. Fitoterapia, 78(7-8), 474-481. . https://doi. org/10.1016/j.fitote.2007.02.013
Rauter, A.P., Dias, C., Martins, A., Branco, I., Neng, N.R., Nogueira, J.M., Goulart, M., Silva, F.V.M., Justino, J., Trevitt, C. (2012). Non-Toxic Salvia sclareoides Brot. extracts as a source of functional food ingredients: Phenolic profile, antioxidant activity and prion binding properties. Food Chemistry, 132(4), 1930-1935. https://doi.org/10.1016/j. foodchem.2011.12.028

Şahin, S., Şamlı, R. (2013). Optimization of olive leaf extract obtained by ultrasound-assisted extraction with response surface methodology. Ultrasonics Sonochemistry, 20(1), 595-602. https://doi. org/10.1016/j.ultsonch.2012.07.029

Schelterns, P., Feldman, H. (2003). Treatment of Alzheimer's Disease: current status and new perspectives. The Lancet Neurology, 2(9), 539-547. https://doi.org/10.1016/S1474-4422(03)00502$\underline{7}$

Silva, E.M., Rogez, H., Larondelle, Y. (2007). Optimization of extraction of phenolics from Inga edulis leaves using response surface methodology. Separation and Purification Technology, 55(3), 381-387. https://doi.org/10.1016/j.seppur.2007.01.008

Stephens, J.M.C., Molan, P.C., Clarkson, B.D. (2005). A review of Leptospermum scoparium (Myrtaceae) in New Zealand. New Zealand Journal of Botany, 43(2), 431-449. https://doi.org/10.1080/002882 5X.2005.9512966

Syad, A.N., Devi, K.P. (2014). Botanics: A potential source of new therapies for Alzheimer's Disease? Botanics, 4: 11. https://doi.org/10.2147/BTAT.S33554

Taylor, J.P., Hardy, J., Fischbeck, K.H. (2002). Toxic proteins in neurodegenerative disease. Science, 296(5575), 1991-1995. https://doi.org/10.1126/ science.1067122

Tian, Y., Xu, Z., Zheng, B., Lo, Y.M. (2013). Optimization of ultrasonic-assisted extraction of pomegranate (Punica granatum L.) seed oil. Ultrasonics and Sonochemistry, 20(1), 202-208. https://doi. org/10.1016/j.ultsonch.2012.07.010

Wang, J., Sun, B., Cao, Y., Tian, Y., Li, X. (2008). Optimisation of ultrasound-assisted extraction of phenolic compounds from wheat bran. Food Chemistry, 106(2), 804-810. https://doi.org/10.1016/j. foodchem.2007.06.062

Yang, Y., Zhang, F. (2008). Ultrasound-assisted extraction of rutin and quercetin from Euonymus alatus (Thunb.) Sieb. Ultrasonics and Sonochemistry, 15(4), 308-313. https://doi.org/10.1016/j. ultsonch.2007.05.001

Yang, L., Cao, Y.L., Jiang, J.G., Lin, Q.S., Chen, J., Zhu, L. (2010). Response surface optimization of ultrasound-assisted flavonoids extraction from the flower of Citrus aurantium L. var. amara Engl. Journal of Separation Science, 33(9), 1349-1355. https://doi.org/10.1002/jssc.200900776 